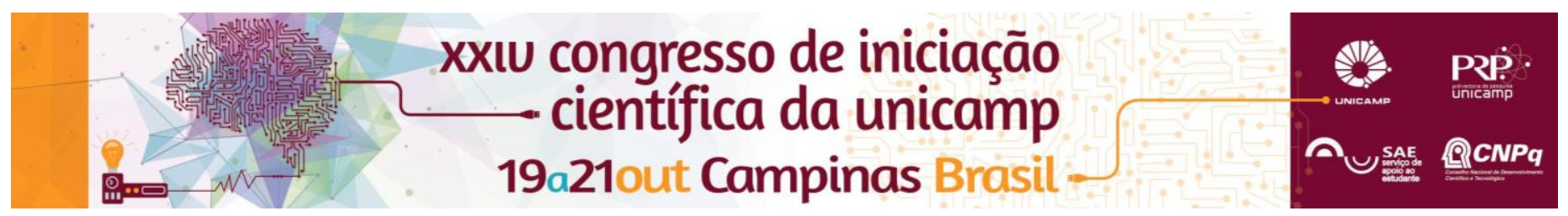

\title{
Fabricação de Máquinas de Prototipagem Rápida
}

\author{
Bruna Cristina De Souza Vieira, Mariana Silvestrine, Monik Wanessa Augusto, Marcelo Z. Maialle
}

\begin{abstract}
Resumo
Este projeto tem como objetivo a integração de alunos do ensino médio nas atividades do Laboratório de Automação e Simulação da Faculdade de Ciências Aplicadas, Unicamp-Limeira, através do desenvolvimento e construção de um protótipo de extrusora de filamentos para impressoras $3 \mathrm{D}$ e de uma máquina de prototipagem rápida (impressora 3D). A extrusão do filamento é uma etapa fundamental no processo de prototipagem, e antecede a impressão tridimensional. Os desafios relacionados a esta fase vão desde a definição do processo, escolha de materiais poliméricos, definição dos equipamentos eletromecânicos até a montagem do protótipo. Durante o projeto, os alunos tiveram contato com a tecnologia de impressão tridimensional, e montaram um kit de impressora 3D. A impressão 3D é bastante discutida atualmente e cuja aplicação faz com que o processo de criação seja mais rápido, e permite soluções geométricas que não são possíveis ou viáveis com os processos de manufatura tradicionais.
\end{abstract}

\author{
Palavras-chave \\ Prototipagem rápida, Impressão 3D, Extrusão.
}

\section{Introdução}

A prototipagem rápida é um conjunto de técnicas modernas de confecção de protótipos usando diretamente os projetos desenvolvidos em computadores. Dentre estas técnicas, focamos na impressão 3D, que é um método "aditivo", no nosso caso, de adição de material plástico na confecção da peça.

Nosso objetivo específico é a montagem de uma impressora 3D utilizando um kit de impressora comercialmente disponível no mercado. Os alunos bolsistas recebem a fundamentação teórica necessária, como conceitos de eletrônica e mecânica, para por em prática na montagem da impressora.

\section{Resultados e Discussão}

Como resultado do trabalho desenvolvido pelo grupo, montamos primeiramente uma extrusora de fios para ser utilizado na impressora 3D. Esta extrusora (Fig.1) aquece e derrete pellets de material plástico, e pressiona este material derretido por um orifício modelando o fio. O kit da extrusora também foi adquirido comercialmente.

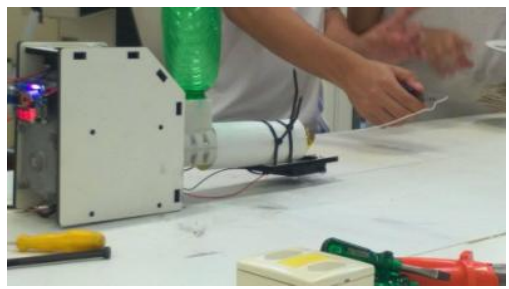

Figura 1. Extrusora de fios em funcionamento
Posteriormente, a montagem da impressora foi realizada (Fig.2). Testes com a impressora ainda estão sendo realizados.

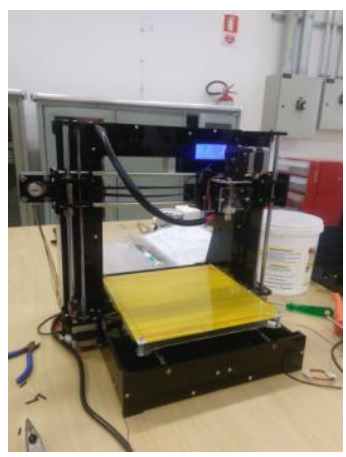

Figura 2. Impressora 3D em montagem

\section{Conclusões}

Utilizamos a montagem de equipamentos de prototipagem rápida para trabalhar conceitos modernos de fabricação com os alunos do ensino médio. A fundamentação conceitual dos objetos de estudo também foi abordada durante a realização do projeto.

\section{Agradecimentos}

Agradecemos ao Laboratório de Automação e Simulação - FCA- Limeira por facilitar a realização deste projeto. 